\title{
The inside story on prison health
}

\author{
Trevor Jackson deputy editor, BMJ
}

\begin{abstract}
The rate of imprisonment in England, Wales, and Scotland-at around 154 per 100000 people - is one of the highest in western Europe. While dwarfed by that of the United States, the so called "land of the free," where roughly one in 100 people is behind bars, the number of prisoners in England and Wales has nearly doubled in the past 20 years, even though recorded crime has fallen. In the final article of his five part series on prison health (BMJ 2013;346:f2216, doi:10.1136/bmj.f2216), Stephen Ginn asks whether prison is the right place for many offenders and whether earlier assistance in the community might prevent a prison sentence.
\end{abstract}

As Ginn writes, many of those held in British prisons "come from the most economically deprived and socially disadvantaged groups within society." He adds: "Many prisoners have chaotic lifestyles and complex health and social problems. They may also have limited health aspirations and low expectations of health services, which may not have the flexibility to respond effectively to their needs."

Prisons, meanwhile, are vulnerable to infectious disease because of overcrowding, poor ventilation, shared facilities, and a high turnover of prisoners, staff, and visitors. They have higher rates of tuberculosis, hepatitis B, and HIV infection than in the outside population, and very high levels of illegal drug use. Ginn says: "Prisons are not principally in the business of promoting health and some people argue that there is an inherent contradiction between the aims of care and control." While prison has a role in meeting the health needs of marginalised people-for example, in 2009-10, 60067 prisoners received clinical treatment for drug addiction in English and Welsh prisons-it is "ultimately not the best place to tackle poor health," writes Ginn.
Moreover, the average cost of a prison place in England and Wales is about $£ 40000$ ( $€ 47000 ; \$ 60000$ ), and in 2012 , UK total prison spend was $£ 4.1 \mathrm{bn}$. While some people clearly need to be in prison, and society understandably demands a custodial sentence for certain - particularly violent — crimes, in most cases couldn't the money be better spent? Ginn says that community based drug treatment, for example, was found to be particularly effective at saving costs "as offenders receiving treatment were $43 \%$ less likely to reoffend after release." If crime were a disease (and indeed some in the public health community have seen it that way), wouldn't the smart money be more on crime prevention rather than the so called cure?

Ginn points out that around $80 \%$ of prisoners in England and Wales smoke, which is four times the proportion of the general public. While there are no plans for British prisons to become smoke free, the switch to e-cigarettes, the topic of Douglas Kamerow's Observations column this week (BMJ 2013;346:f3418, doi:10.1136/bmj.f3418), might at least improve the environment for non-smoking prisoners. However, as Kamerow writes, e-cigarettes are worrying the public health community. They appear to help maintain the smoking habit and reduce incentives to quit, and now Big Tobacco is moving into the e-cigarette market. "Now that the vapour is fully out of the cartridge, we're not going to be able to get it back in," says Kamerow. "We need to make the best of a bad situation before it gets worse."

Cite this as: BMJ 2013;346:f3471

๑๑ BMJ Publishing Group Ltd 2013 